\title{
Effective connecting architecture for tandem organic light-emitting devices
}

\author{
Chieh-Wei Chen \\ Graduate Institute of Electro-Optical Engineering, National Taiwan University, Taipei, Taiwan \\ 10617, Republic of China and Department of Materials Science and Engineering, University of California, \\ Los Angeles, California 90095 \\ Yin-Jui Lu and Chung-Chih Wua) \\ Graduate Institute of Electro-Optical Engineering, National Taiwan University, Taipei, Taiwan 10617, \\ Republic of China \\ Elbert Hsing-En Wu, Chih-Wei Chu, and Yang Yang ${ }^{\text {a) }}$ \\ Department of Materials Science and Engineering, University of California, Los Angeles, California 90095
}

(Received 1 October 2005; accepted 4 November 2005; published online 9 December 2005)

\begin{abstract}
An effective connecting structure for tandem organic light-emitting devices is reported. The connecting structure consists of a thin metal layer as the common electrode, a hole-injection layer containing $\mathrm{MoO}_{3}$ on one side of the common electrode, and an electron-injection layer involving $\mathrm{Cs}_{2} \mathrm{CO}_{3}$ on the other side. Such a connecting structure permits efficient opposite hole and electron injection into two adjacent emitting units and gives tandem devices superior electrical and optical performances. Furthermore, the present connecting structure involves no sputtering or handling of reactive metals during device fabrication and can be prepared purely by thermal evaporation, thus rendering device processing more feasible. (C) 2005 American Institute of Physics.
\end{abstract}

[DOI: $10.1063 / 1.2141718]$

Organic light-emitting devices (OLEDs) having multiple emitting units stacked vertically in series, i.e., tandem OLEDs, are recently reported to be useful for providing high luminance, for enhancing the current (cd/A) efficiency, and for conveniently tuning the emission spectra of devices through stacking units emitting different colors. ${ }^{1-3}$ The major challenge in tandem OLEDs in general is to prepare the effective connecting structure between emitting units so that the current can smoothly flow through without facing substantial barriers. Conceptually the configuration of tandem OLEDs is like electrically connecting OLEDs in series. Thus the straightforward thinking of forming a connecting structure is to place the anode electrode of the upper unit on top of the cathode electrode of the lower unit. Indeed, in few reported configurations of tandem OLEDs, the connecting structures in general consist of a hole-injecting conductive layer for hole injection into the upper unit and an electroninjecting conductive layer for opposite electron injection into the unit beneath. The hole-injecting conductive layers used thus far include inorganic materials such as indium tin oxide (ITO) and $\mathrm{V}_{2} \mathrm{O}_{5}$, or organic hole-transport layers with $p$-type conductive doping. ${ }^{1-3}$ On the other hand, the electroninjecting conductive layers used in the connecting structure of tandem OLEDs thus far all involve organic electrontransport layers with $n$-type conductive doping (i.e., using reactive low-work-function metals as $n$-type dopants). ${ }^{1-3}$

An alternative design of the connecting structure, which is less straightforward but would be structurally simpler, is to combine the functions of these two conductive layers into one common electrode that is capable of opposite hole and electron injection into two neighboring units. In this letter, we report an effective connecting structure for tandem OLEDs based on such a concept. Furthermore, unlike previ-

\footnotetext{
a) Authors to whom correspondence should be addressed; electronic mail: yangy@ucla.edu, chungwu@cc.ee.ntu.edu.tw
}

ously reported connecting structures that involve relatively complicated sputtering or handling of reactive low-workfunction metals in fabrication, the connecting structures reported in this letter use no reactive metals and can be prepared purely with thermal evaporation.

Metals such as $\mathrm{Ag}$ and $\mathrm{Al}$ are the preferred common connecting electrode, since they are air-stable and could be thermally evaporated. Yet, $\mathrm{Ag}$ and $\mathrm{Al}$ in general are not ideal hole-injecting and electron-injecting electrodes for OLEDs, and thus carrier-injection schemes that are not sensitive to electrode materials must first be developed. In 2004, Canon Inc. reported that cesium carbonate $\left(\mathrm{Cs}_{2} \mathrm{CO}_{3}\right)$, either vacuum-deposited as an individual layer over the organic electron-transport material or codeposited with the organic electron-transport material, effectively facilitates electron injection from a wide range of metal electrodes. ${ }^{4}$ Furthermore, unlike reactive low-work-function metals, $\mathrm{Cs}_{2} \mathrm{CO}_{3}$ requires no special care or equipments for handling and thus is more convenient. Since Cannon Inc. did not disclose the electron-transport material used in their studies, here a few device structures were fabricated and tested to evaluate whether $\mathrm{Cs}_{2} \mathrm{CO}_{3}$ is useful with other widely used electron-transport materials such as tris(8hydroxyquinolate)aluminum $\left(\mathrm{Alq}_{3}\right) .^{5} \quad$ These include: (1) devices using $\mathrm{Alq}_{3}$ doped with $20 \mathrm{wt} . \%$ of $\mathrm{Cs}_{2} \mathrm{CO}_{3}$ as the electron-injection layer [ITO/PEDT:PSS $(20 \mathrm{~nm}) / \alpha$-NPD $\quad(40 \mathrm{~nm}) / \mathrm{Alq}_{3} \quad(40 \mathrm{~nm}) / \mathrm{Alq}_{3}: \mathrm{Cs}_{2} \mathrm{CO}_{3}$ $(20 \mathrm{~nm}) / \mathrm{Al}$ (device E1) or Ag (device E2)]; (2) devices using a thin layer of $\mathrm{Cs}_{2} \mathrm{CO}_{3}$ as the electron-injection layer [ITO/PEDT:PSS $(20 \mathrm{~nm}) / \alpha$-NPD $\quad(40 \mathrm{~nm}) / \mathrm{Alq}_{3}$ $(60 \mathrm{~nm}) / \mathrm{Cs}_{2} \mathrm{CO}_{3}(1 \mathrm{~nm}) / \mathrm{Al}$ (device E3) or Ag (device E4)]; (3) devices using no electroinjection layer [ITO/PEDT:PSS $(20 \mathrm{~nm}) / \alpha$-NPD $(40 \mathrm{~nm}) / \mathrm{Alq}_{3}(60 \mathrm{~nm}) / \mathrm{Al}$ (device E5) or $\mathrm{Ag}$ (device E6)]; (4) a "benchmark" device (device E7) using $\mathrm{LiF}$ as the electron-injection layer [ITO/PEDT:PSS $(20 \mathrm{~nm}) / \alpha$-NPD $\left.(40 \mathrm{~nm}) / \mathrm{Alq}_{3}(60 \mathrm{~nm}) / \mathrm{LiF}(0.5 \mathrm{~nm}) / \mathrm{Al}\right]$. 

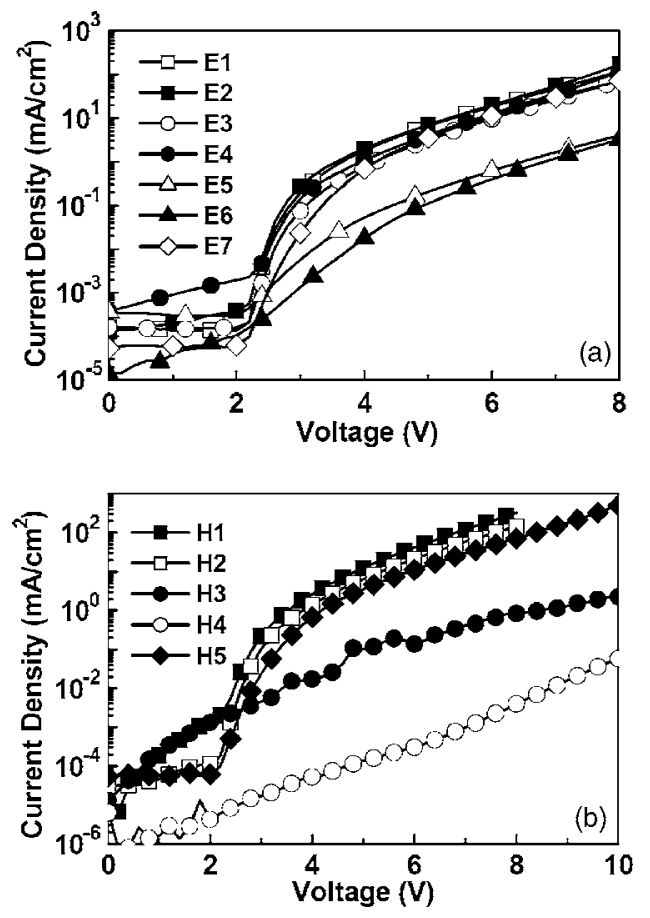

FIG. 1. $I-V$ characteristics of (a) devices $E 1-E 7$ and (b) devices $H 1-H 5$.

In these devices, the conducting polymer PEDT:PSS [poly(ethylene dioxythiophene)/poly(styrene sulphonate)] and $\alpha$-NPD $\quad\left\{4,4^{\prime}\right.$-bis $[N$-(1-naphyl)- $N$-phenyl-amino $]$ biphenyl $\}$ are used as the hole-injection and hole-transport layers, respectively. ${ }^{6,7}$ PEDT:PSS was prepared by spin coating and all other layers were vacuum deposited in sequence without breaking the vacuum. $I-V$ characteristics of these devices are shown in Fig. 1(a), in which one clearly sees that $\mathrm{Cs}_{2} \mathrm{CO}_{3}$, either vacuum deposited as a thin layer over $\mathrm{Alq}_{3}$ or codeposited with $\mathrm{Alq}_{3}$, effectively facilitates electron injection from both $\mathrm{Ag}$ and $\mathrm{Al}$, and that the performances are comparable to or even better than that obtained with the benchmark scheme (i.e., using $\mathrm{LiF} / \mathrm{Al})^{5}$

Next, schemes for hole-injection from $\mathrm{Ag}$ or $\mathrm{Al}$ into typical hole-transport materials such as $\alpha$-NPD are considered. Previous reports revealed that $\mathrm{MoO}_{3}$ is a wide-gap (and thus transparent) material with a band gap of $\sim 3.1 \mathrm{eV}$ and is a superb hole-injection material for ITO. ${ }^{8}$ Furthermore, $\mathrm{MoO}_{3}$ can be conveniently deposited by thermal evaporation and evaporated $\mathrm{MoO}_{3}$ forms a transparent and homogeneous film, making it rather compatible with the OLED fabrication. Here we evaluate the use of $\mathrm{MoO}_{3}$ as a hole-injection material for $\mathrm{Ag}$ or $\mathrm{Al}$ with the following device structures: (1) devices using $\mathrm{MoO}_{3}$ as the hole-injection layer [100 nm Al (device $H 1)$ or $\mathrm{Ag}$ (device $H 2) / \mathrm{MoO}_{3}(5 \mathrm{~nm}) / \alpha$-NPD $\left.(40 \mathrm{~nm}) / \mathrm{Alq}_{3}(60 \mathrm{~nm}) / \mathrm{LiF}(0.5 \mathrm{~nm}) / \mathrm{Al}\right]$; (2) devices using no hole-injection layer $[100 \mathrm{~nm} \mathrm{Al}$ (device H3) or $\mathrm{Ag}$ (device $H 4) / \alpha$-NPD $\quad(40 \mathrm{~nm}) / \mathrm{Alq}_{3} \quad(60 \mathrm{~nm}) / \mathrm{LiF}$ (0.5 nm)/Al]; (3) a benchmark device (device H5) using ITO and PEDT:PSS as the anode and the hole-injection layer, respectively [ITO/PEDT:PSS $(20 \mathrm{~nm}) / \alpha$-NPD $\left.\left.(40 \mathrm{~nm}) / \mathrm{Alq}_{3}(60 \mathrm{~nm}) / \mathrm{LiF}(0.5 \mathrm{~nm}) / \mathrm{Al}\right)\right] . I-V$ characteristics of these devices are shown in Fig. 1(b), in which one clearly sees that $\mathrm{MoO}_{3}$ combined with the $\mathrm{Ag}$ or $\mathrm{Al}$ anode effectively facilitates hole injection from both $\mathrm{Ag}$ and $\mathrm{Al}$, and gives better electrical characteristics than the benchmark

scheme (i.e., ITO/PEDT:PSS). (with the connecting structure of $\mathrm{Alq}_{3}: \mathrm{Cs}_{2} \mathrm{CO}_{3} / \mathrm{Al}_{\text {or }}$ or
Downloaded 17 Feb 2009 to 140.112.113.225. Redistribution subject to AlP license or copyright; see http://apl.aip.org/apl/copyright.jsp
Using these carrier-injection schemes, various two-unit tandem devices adopting different connecting structures were constructed, including: (1) device TA: ITO/PEDT:PSS $(20 \mathrm{~nm}) / \alpha$-NPD $\quad(40 \mathrm{~nm}) / \mathrm{Alq}_{3} \quad(40 \mathrm{~nm}) / \mathrm{Alq}_{3}: \mathrm{Cs}_{2} \mathrm{CO}_{3}$ $(20 \mathrm{~nm}) / \mathrm{Al}(5 \mathrm{~nm}) / \mathrm{MoO}_{3}(5 \mathrm{~nm}) / \alpha-\mathrm{NPD} \quad(40 \mathrm{~nm}) / \mathrm{Alq}_{3}$ $(60 \mathrm{~nm}) / \mathrm{Cs}_{2} \mathrm{CO}_{3}(1 \mathrm{~nm}) / \mathrm{Al}$; (2) device $T B$ : ITO/PEDT:PSS $(20 \mathrm{~nm}) / \alpha$-NPD $\quad(40 \mathrm{~nm}) / \mathrm{Alq}_{3} \quad(40 \mathrm{~nm}) / \mathrm{Alq}_{3}: \mathrm{Cs}_{2} \mathrm{CO}_{3}$ $(20 \mathrm{~nm}) / \mathrm{Al}(1 \mathrm{~nm}) / \mathrm{MoO}_{3}(5 \mathrm{~nm}) / \alpha-\mathrm{NPD}(40 \mathrm{~nm}) / \mathrm{Alq}_{3}$ $(60 \mathrm{~nm}) / \mathrm{Cs}_{2} \mathrm{CO}_{3}(1 \mathrm{~nm}) / \mathrm{Al}$; (3) device $T C$ : ITO/PEDT:PSS $(20 \mathrm{~nm}) / \alpha$-NPD $\quad(40 \mathrm{~nm}) / \mathrm{Alq}_{3} \quad(40 \mathrm{~nm}) / \mathrm{Alq}_{3}: \mathrm{Cs}_{2} \mathrm{CO}_{3}$ $(20 \mathrm{~nm}) / \mathrm{Ag}(1 \mathrm{~nm}) / \mathrm{MoO}_{3}(5 \mathrm{~nm}) / \alpha-\mathrm{NPD}(40 \mathrm{~nm}) / \mathrm{Alq}_{3}$ $(60 \mathrm{~nm}) / \mathrm{Cs}_{2} \mathrm{CO}_{3} \quad(1 \mathrm{~nm}) / \mathrm{Ag} ; \quad$ (4) device TD: ITO/ PEDT:PSS $\quad(20 \mathrm{~nm}) / \alpha$-NPD $\quad(40 \mathrm{~nm}) / \mathrm{Alq}_{3}$ $(40 \mathrm{~nm}) / \mathrm{Alq}_{3}: \mathrm{Cs}_{2} \mathrm{CO}_{3} \quad(20 \mathrm{~nm}) / \mathrm{MoO}_{3} \quad(5 \mathrm{~nm}) / \alpha$-NPD $(40 \mathrm{~nm}) / \mathrm{Alq}_{3}(60 \mathrm{~nm}) / \mathrm{Cs}_{2} \mathrm{CO}_{3}(1 \mathrm{~nm}) / \mathrm{Al}$. All devices were fabricated on the cleaned and UV-ozone-treated ITO glass substrates, using PEDT/PSS as the hole-injection layer and an ultrathin $\mathrm{Cs}_{2} \mathrm{CO}_{3}(1 \mathrm{~nm})$ layer as the electroninjection layer for the top metal cathode. Each emitting unit consists of $\alpha$-NPD as the hole-transport layer and $\mathrm{Alq}_{3}$ as the electron-transport and emitting layer.

As an initial try, tandem device $T A$ using the connecting structure of $\mathrm{Alq}_{3}: \mathrm{Cs}_{2} \mathrm{CO}_{3}(20 \mathrm{~nm}) / \mathrm{Al}(5 \mathrm{~nm}) / \mathrm{MoO}_{3}(5 \mathrm{~nm})$ was fabricated and tested. Its $I-V-L$ and efficiency characteristics are compared with those of the single-unit device $E 3$ in Fig. 2. As one would expect for an ideal two-unit tandem device that should behave like two single-unit devices interconnected in series, device $T A$ exhibits a driving voltage roughly double of the single-unit device voltage, indicating the effectiveness of the present connecting structure on the electrical aspect (i.e., hole and electron injection into the top and the bottom units, respectively). Since one would also expect an efficiency doubling for a well-behaved two-unit tandem device, the efficiency of device $T A(\sim 5.8 \mathrm{~cd} / \mathrm{A}$, only 1.5 times higher than $3.8 \mathrm{~cd} / \mathrm{A}$ of the single-unit device E3) is not satisfactory. The efficiency loss is most probably caused by absorption and reflection of the thin metal layer $(5 \mathrm{~nm})$ in the connecting structure. Thus, in an effort to further improve the tandem device performances, the tandem device $T B$ using an even thinner metal layer $(1 \mathrm{~nm})$ in the connecting structure [i.e., $\mathrm{Alq}_{3}: \mathrm{Cs}_{2} \mathrm{CO}_{3} \quad(20 \mathrm{~nm}) / \mathrm{Al}$ $\left.(1 \mathrm{~nm}) / \mathrm{MoO}_{3}(5 \mathrm{~nm})\right]$ was tested. As shown in Fig. 2, electrical characteristics of $T B$ remain same as those of $T A$, yet its efficiency $(\sim 8.3 \mathrm{~cd} / \mathrm{A})$ is successfully raised to double (indeed more than double) of $E 3$ efficiency. As demonstrated in Fig. 1, the effectiveness of MoO3 for enhancing hole injection and $\mathrm{Cs}_{2} \mathrm{CO}_{3}$ for enhancing electron injection is valid for both $\mathrm{Al}$ and $\mathrm{Ag}$; thus replacing $\mathrm{Al}$ with $\mathrm{Ag}$ in the connecting structure (i.e., comparing device $T B$ and $T C$ ) gives equally efficient tandem device $T C$. Finally, one notices that removing the thin metal layer in the connecting structure (i.e., device $T D$ ) substantially raises device voltage (nearly triple of $E 3$ voltage), indicating the indispensable role of the thin metal layer in electrically connecting the two emitting units.

The preliminary test of the operational stability of tandem devices was also performed. The measurement was performed under the dry nitrogen atmosphere by applying a constant current $\left(21.5 \mathrm{~mA} / \mathrm{cm}^{2}\right)$ to devices. Figure 3 shows the normalized luminance as a function of the driving time for devices $E 3, T B, T C$, and $T D$. Tandem devices $T B$ and $T C$ (with the connecting structure of $\mathrm{Alq}_{3}: \mathrm{Cs}_{2} \mathrm{CO}_{3} / \mathrm{Al}$ or o AlP license or copyright; see http://apl.aip.org/apl/copyright.jsp 

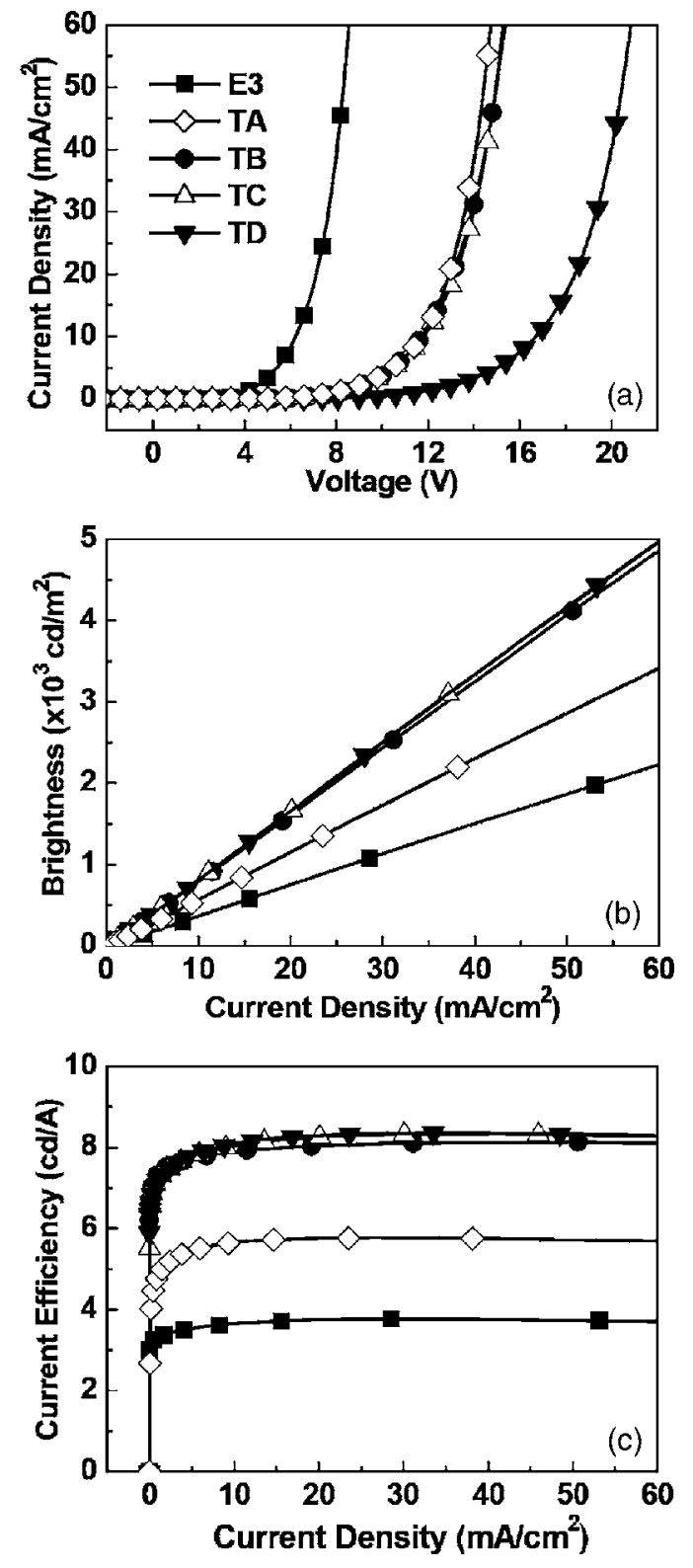

FIG. 2. (a) $I-V$, (b) $L-I$, and (c) cd/A efficiency vs current characteristics of the single-unit device $E 3$ and tandem devices $T A, T B, T C$, and $T D$.

$\mathrm{Ag} / \mathrm{MoO}_{3}$ ) clearly exhibit a slower rate of brightness degradation (and thus improved operational stability) than the single-unit device $E 3$. In contrast, tandem device $T D$, which adopts the connecting structure of $\mathrm{Alq}_{3}: \mathrm{Cs}_{2} \mathrm{CO}_{3} / \mathrm{MoO}_{3}$ (with no intermediate ultrathin metal layer), exhibits a rapid drop of luminance at a very early stage. Thus, in comparison with $\mathrm{Alq}_{3}: \mathrm{Cs}_{2} \mathrm{CO}_{3} / \mathrm{MoO}_{3}$, the connecting structure $\mathrm{Alq}_{3}: \mathrm{Cs}_{2} \mathrm{CO}_{3} / \mathrm{Al}$ or $\mathrm{Ag} / \mathrm{MoO}_{3}$ not only gives better electrical performances but also show enhanced robustness under continuous operation.

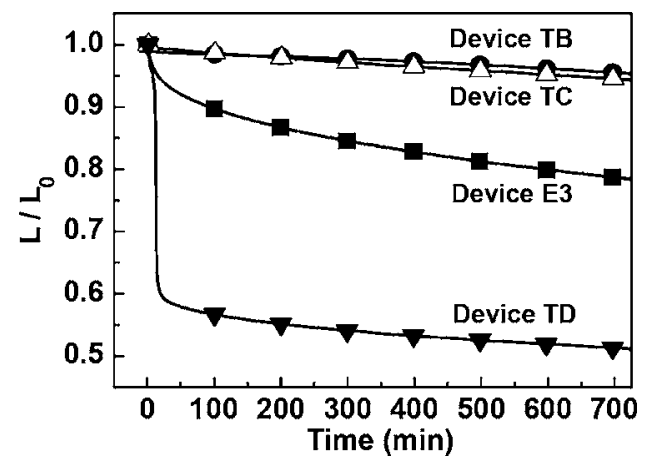

FIG. 3. Normalized luminance [luminance $(L)$ /initial luminance $\left.\left(L_{0}\right)\right]$ as a function of the driving time for devices $E 3, T B, T C$, and $T D$, under a constant driving current of $21.5 \mathrm{~mA} / \mathrm{cm}^{2}$.

In summary, we report an effective connecting structure for tandem OLEDs. The connecting structure consists of a thin metal layer as the common electrode, a hole-injection layer on one side of the common electrode and an electroninjection layer on the other side. Such a connecting structure permits efficient opposite hole and electron injection into two adjacent emitting units and gives tandem devices superior electrical and optical performances. Furthermore, the present connecting structure involves no sputtering or handling of reactive metals during device fabrication and thus renders device processing more feasible.

The authors would like to acknowledge financial support from National Science Council of Republic of China (C.-C.W.) and from the National Science Foundation (Y.Y.), respectively. The authors also wish to thank Professor Junji Kido for technical discussions and e-Ray Optoelectronics Technology for providing organic materials. C.-W.C is also grateful for financial support from MediaTek Fellowship.

${ }^{1}$ J. Kido, T. Nakada, J. Endo, N. Kawamura, K. Mori, A. Yokoi, and T. Matsumoto, Proceedings of the 11th International Workshop on Inorganic and Organic Electroluminescence and 2002 International Conference on the Science and Technology of Emissive Displays and Lighting, Universiteit Ghent, Ghent, Belgium, 2002, p. 539.

${ }^{2}$ T. Matsumoto, T. Nakada, J. Endo, K. Mori, N. Kavamura, A. Yokoi, and J. Kido, 2003 Society for Information Display (SID) International Symposium, Digest of Technical Papers, Baltimore, MD, 2003, p. 979.

${ }^{3}$ L. S. Liao, K. P. Klubek, and C. W. Tang, Appl. Phys. Lett. 84, 167 (2004).

${ }^{4}$ T. Hasegawa, S. Miura, T. Moriyama, T. Kimura, I. Takaya, Y. Osato, and H. Mizutani, 2004 Society for Information Display (SID) International Symposium, Digest of Technical Papers, Seattle, WA, 2004, p. 154.

${ }^{5}$ L. S. Hung, C. W. Tang, and M. G. Mason, Appl. Phys. Lett. 70, 152 (1997).

${ }^{6}$ A. Elschner, F. Bruder, H. W. Heuer, F. Jonas, A. Karbach, S. Kirchmeyer, S. Thurm, and R. Wehrmann, Synth. Met. 111-112, 139 (2000).

${ }^{7}$ J. Shi and C. W. Tang, Appl. Phys. Lett. 70, 1665 (1997).

${ }^{8}$ S. Tokito, K. Noda, and Y. Taga, J. Phys. D 29, 2750 (1996). 